\title{
Animales Domésticos Como Reservorio De Escherichia coli Productor De Toxina Shiga En Mar del Plata
}

\section{Pets as Reservoir Escherichia coli Shiga Toxin-Producer in Mar del Plata}

\author{
Zotta Claudio Marcelo ${ }^{1 *}$, Lavayén Silvina ${ }^{2}$, Hollmann Patricia $^{3}$, Lanfranconi Viviana ${ }^{4}$
}

\section{Datos del Artículo \\ ${ }^{1}$ Instituto Nacional de Epidemiología "Dr. Juan H. Jara" (INE)-Administraci- ón Nacional de Laboratorios e Institu- tos de Salud "Carlos G. Malbrán" (AN- LIS), Ministerio de Salud de la Nación Argentina. Ituzaingó 3520 - Mar de Plata, Argentina. 0223-4733449. \\ 2 Instituto Nacional de Epidemiología "Dr. Juan H. Jara", INE - ANLIS "Car- los G. Malbrán", Ministerio de Salud de la Nación Arentinerio de Salud de la Nación Argentina. Iluzaingó 35- 20-Mar 4733449. vayensil@hotmail.com \\ ${ }^{3}$ Municipalidad del Partido de General Pueyrredón, Departamento de Zoono- sis. Hernandarias 10200 - Mar del Pla- ta, Argentina. 0223- 4652510. Patoho- llmann@hotmail.com \\ ${ }^{4}$ Municipalidad del Partido de General Pueyrredón, Departamento de Zoono- sis. Hernandarias 10200 - Mar del Pla- ta, Argentina. 0223- 4652510 \\ vivilanf@hotmail.com \\ *Dirección de contacto Claudio Marcelo Zotta: Instituto Naci- onal de Epidemiología "Dr. Juan H. Jara". INE - ANLIS "Carlos G. Mal- brán", Ministerio de Salud de la Nación Argentina. Ituzaingó 3520 - Mar del Plata, Argentina. 0223-4733449. \\ E-mail address : \\ marcelozotta@hotmail.com}

\section{Palabras clave:}

Escherichia coli productor de toxina Shiga,

síndrome urémico hemolítico,

animales de compañía,

reservorio,

PCR múltiple.

\section{J. Selva Andina Res. Soc.} 2015; 6(1):2-9.

\section{Historial del artículo.}

Recibido, octubre, 2014 Devuelto, noviembre 2014

Aceptado, febrero, 2015

Disponible en línea, febrero, 2015

\section{Resumen}

Escherichia coli productor de toxina Shiga (STEC) es un patógeno emergente a nivel mundial siendo reconocido como agente causal de enfermedades severas en el hombre, como colitis hemorrágica $(\mathrm{CH})$ y síndrome urémico hemolítico (SUH).

El objetivo consistió en determinar el rol de los animales de compañía como potenciales reservorios de STEC en la cadena epidemiológica del SUH.

Se realizó un estudio descriptivo de corte transversal. Entre octubre de 2010 y abril de 2013 se procesaron 162 muestras de perros y gatos realizándose PCR múltiple para la detección de los genes $s t x_{1}$, st $x_{2}$ y $r f b_{0157}$, no detectándose señal positiva por PCR en ninguna de las muestras procesadas.

Estos resultados de ausencia de STEC en los animales estudiados podría deberse a que la alimentación de los mismos resultó principalmente con alimentos balanceados ya que el consumo de alimentos contaminados, como por ejemplo carne molida, productos cárnicos crudos o insuficientemente cocidos, constituyen una de las principales fuentes de infección para este microorganismo.

(C) 2015. Journal of the Selva Andina Research Society. Bolivia. Todos los derechos reservados.

\section{Abstract}

Escherichia coli Shiga toxin-producer (STEC) is an emerging pathogen worldwide being recognized as a cause of severe human diseases, such as hemorrhagic colitis (HC) and hemolytic uremic syndrome (HUS).

The aim of this work was to determine the role of companion animals as potential reservoirs of STEC in the epidemiological chain of HUS.

A descriptive cross-sectional study was conducted. Between October 2010 and April 2013, samples from 162 dogs and cats were processed performing multiplex PCR for detection of stx 1 , stx 2 and rfbO157 genes. Was not detect- 


\begin{tabular}{|c|c|}
\hline $\begin{array}{c}\text { Editado por: } \\
\text { Selva Andina } \\
\text { Research Society }\end{array}$ & $\begin{array}{l}\text { ed positive signal by PCR in any of the processed samples. } \\
\text { These results from the absence of STEC in animals studied could be because feeding them with feed resulted } \\
\text { primarily because the consumption of contaminated foods, such as ground beef, meat products raw or under- } \\
\text { cooked, constitutes a major infection source for this microorganism. }\end{array}$ \\
\hline Key words: & \\
\hline $\begin{array}{l}\text { Escherichia coli Shiga } \\
\text { toxin-producer, } \\
\text { hemolytic uremic syn- } \\
\text { drome, } \\
\text { Pets, } \\
\text { reservoir, } \\
\text { multiplex PCR. }\end{array}$ & (C) 2015. Journal of the Selva Andina Research Society. Bolivia. All rights reserved. \\
\hline
\end{tabular}

\section{Introducción}

Escherichia coli productor de toxina Shiga (STEC) es un patógeno emergente a nivel mundial siendo reconocido como agente causal de enfermedades severas en el humano, como colitis hemorrágica $(\mathrm{CH})$ y síndrome urémico hemolítico (SUH). Múltiples serotipos de STEC han sido asociados a estas patologías y a enfermedades transmitidas por alimentos en distintas partes del mundo, con evidencia de que una gran proporción de los casos se deben a serotipos distintos del prototipo O157:H7 (Franke et al. 1995).

Los registros oficiales de Argentina muestran que el SUH es endémico y presenta la mayor incidencia en el mundo, con un reporte de más de 10 casos/100000 niños menores de 5 años en la última década y aproximadamente 400 casos anuales (Rivas et al. 2011).

Los mecanismos de transmisión de Escherichia coli O157:H7 y otros STEC comprenden el consumo de alimentos y aguas contaminadas, contacto directo con animales portadores o sus heces y transmisión de persona a persona (Griffin \& Tauxe 1991, Doyle et al. 1997). Los avances en el conocimiento de esta patología, especialmente en los aspectos etiológicos, conllevan la necesidad de investigar no sólo lo vin culado a los hábitos alimentarios de la población, sino al contacto con animales que son considerados de compañía para los niños. El ganado bovino es considerado el reservorio principal de este patógeno (Nataro et al. 1998). Se han aislado cepas STEC de animales domésticos sanos como cabras, ovejas, cerdos, gatos y perros, hallando una prevalencia del $13.8 \%$ en gatos y $4.8 \%$ de perros (Beutin et al. 1993). También se han aislado a partir de gaviotas (Kobayami et al. 1999), conejos, pollos.

En Argentina se ha detectado la presencia de STEC en un $4.0 \%$ en perros y $4.2 \%$ en gatos (Gallego et al. 2006). Similar porcentaje (4.3\%) se detectó en otro trabajo (Bentancor et al. 2006) en caninos y felinos.

STEC O157:H7 fue aislado de un perro asintomático que mantuvo contacto con un equino y un humano infectado con este serotipo (Trevena et al. 1996).

En la ciudad de Mar del Plata, según el Departamento de Zoonosis de la Municipalidad del Partido de General Pueyrredón, se estima que la proporción es aproximadamente de 1 perro por cada 6 personas con una dispersión de la población canina estimada en 1 animal por cada 10 personas para la zona céntrica de la ciudad mientras que la relación sería $1 / 2$ 
para las zonas periféricas. Los datos del último censo en Argentina (Instituto Nacional de Estadísticas y Censos 2010) establecieron que la población para el Partido de General Pueyrredón era de 618989 habitantes.

La dinámica de STEC, en su relación reservoriomedio ambiente, no está totalmente dilucidada. Por ello, constituye un desafío epidemiológico alcanzar un mayor conocimiento de la frecuencia de portación de este microorganismo en reservorios menos frecuentes.

El objetivo del trabajo consistió en describir el rol de los animales de compañía como potenciales reservorios de Escherichia coli productor de toxina Shiga (STEC) en la cadena epidemiológica del Síndrome Urémico Hemolítico.

\section{Materiales y métodos}

Se realizó un estudio descriptivo de corte transversal para caracterizar el perfil de la población en estudio y la presencia/ausencia de STEC.

Para el trabajo se realizó un muestreo por conveniencia. La toma de muestra se efectuó a los primeros cinco animales que concurrieron a la consulta el primer día hábil de cada semana comprendida dentro del período de estudio.

Las variables sometidas a estudio fueron: edad, sexo y raza de los animales, tipo de alimentación categorizada como alimento balanceado (de elaboración comercial definido como alimento balanceado completo y equilibrado que contiene todos los nutrientes esenciales que satisfacen todos los requerimientos del animal) y no balanceado, lugar de residencia del animal, síntoma de diarrea en el propietario como en su familia en los quince días previos a la toma de muestra en la mascota, síntoma de diarrea en el animal en los quince días previos a la toma de muestra, cohabitabilidad de los animales con seres humanos (definido como el contacto con humanos adultos, niños o ambos) y detección de STEC.

Entre octubre de 2010 y abril de 2013 el Centro Municipal de Zoonosis y el Quirófano Móvil dependiente del mismo, tomaron y procesaron 162 muestras de materia fecal obtenidas por hisopado rectal y conservadas en medio de transporte Cary Blair (Britania, Buenos Aires, Argentina), de animales de compañía (96 perros y 66 gatos) citados para cirugía de castración (ovariohisterectomía u orquiectomía), previo consentimiento informado del dueño del animal. Simultáneamente se completó una ficha de toma de muestra y envío de la misma, confeccionada específicamente para tal fin, donde se consignaron los datos del animal en estudio.

Para la detección de STEC las muestras de materia fecal fueron sembradas en placas de agar MacConkey con sorbitol (SMAC) (Difco, Laboratorios, Detroit, MI, EE.UU.) las cuales fueron incubadas a $37^{\circ}$ $\mathrm{C}$ durante $18 \mathrm{~h}$, por cultivo directo y luego del enriquecimiento por incubación de $6 \mathrm{~h}$ a $37^{\circ} \mathrm{C}$ en caldo tripticasa soya (CTS) (Britania) suplementado con $50 \mathrm{mg} / \mathrm{L}$ de cefixima y $2.5 \mathrm{mg} / \mathrm{L}$ de telurito de potasio (bioMérieux Marcy/Étoile, France) (CT-CTS) (Leotta et al. 2006).

Las placas de cultivo sembradas fueron enviadas al Servicio de Bacteriología del Laboratorio de Diagnóstico y Referencia del Instituto Nacional de Epidemiología "Dr. Juan H. Jara” - ANLIS "Dr. Carlos G. Malbrán", en donde se realizó a partir de la zona de confluencia y de 10 colonias elegidas al azar de las placas de primo aislamiento la detección de los genes de toxina Shiga $s t x_{1}, s t x_{2}$ y $r f b_{0157}$, mediante técnica de reacción de la polimerasa en cadena (PCR) múltiple (Leotta et al. 2005). Las colonias seleccionadas se suspendieron en 150 L de solución de tritón X-100 (Promega, Madison, WI, EE.- 
UU.) al $1 \%$ en buffer TE $1 X$. Se centrifugaron a $10000 \mathrm{rpm}$ durante $5 \mathrm{~min}$ luego de hervir en baño de agua a $100^{\circ} \mathrm{C}$ durante $15 \mathrm{~min}$. El extracto de $\mathrm{ADN}$ se conservó a $4^{\circ} \mathrm{C}$ para ser utilizado como templado.

Para realizar la PCR múltiple se utilizaron tres pares de oligonucleótidos iniciadores para amplificar fragmentos de los genes $s t x_{1}$, stx $x_{2}$ y $r f b_{0157}$ : stx $1 \mathrm{a}$ (5'-GAAGAGTCCGTGGGATTACG-3'), stx1b (5'-AGCGATGCAGCTATTAATAA-3'), stx2a (5'-TTAACCACACCCCACCGGGCAGT-3'), stx2b (5'-GCTCTGGATGCATCTCTGGT-3'), O157F (5'- CGGACATCCATGTGATATGG-3') y O157R (5'-TTGCCTATGTACAGCTAATCC-3'), cuyos tamaños de los fragmentos de amplificación fueron 130, 346 y 259 pares de bases respectivamente. Se utilizaron 50 L finales de mezcla de reacción de PCR, conteniendo 5 L de Buffer PCR 10X (Invitrogen Life Technologies, Brasil), 2 L de mezcla de dNTPs $2.5 \mathrm{mM}$ (Promega), $1.5 \quad \mathrm{~L}$ de $\mathrm{Cl}_{2} \mathrm{Mg} 50$ Mm (Invitrogen), 1 L del par de oligonucleótidos iniciadores Stx1 $0.1 \mathrm{nmol} / \mathrm{L}$ (Invitrogen), $0.2 \mathrm{~L}$ de los pares de oligonucleótidos iniciadores Stx2 0.1 nmol/ L (Invitrogen), 0.3 L de los pares de oligonucleótidos iniciadores $01570.1 \mathrm{nmol} / \mathrm{L}$ (Invitrogen), $0.2 \mathrm{~L}$ de $T a q$ polimerasa $5 \mathrm{U} / \mathrm{mL}$ (Invitrogen), 36.3 L de agua tridestilada estéril y finalmente 2 $\mathrm{L}$ de ADN templado. Como control positivo y negativo se utilizó el ADN templado de las cepas $E$. coli EDL933 O157:H7 stx1/stx2 y E. coli ATCC $25922 \sin$ factores de virulencia, respectivamente. Además se utilizaron 50 L de mezcla de reacción de PCR sin ADN templado como control de sistema. Se utilizó un termociclador Multigene TC9600 (Labnet, Edison, NJ, EE.UU.). Las condiciones de amplificación fueron $94^{\circ} \mathrm{C}$ por $5 \mathrm{~min}$, seguido de 30 ciclos a $94^{\circ} \mathrm{C}$ por $30 \mathrm{~s}, 58^{\circ} \mathrm{C}$ por $30 \mathrm{~s}$ y $72^{\circ} \mathrm{C}$ por $30 \mathrm{~s}$. La extensión final fue a $72^{\circ} \mathrm{C}$ por $2 \mathrm{~min}$. 5
Se agregaron 10 L de una solución de xilene cyanol $0.25 \%$ y glicerol en agua $30 \%$ (Sigma, St Louis, EE.UU.) a $50 \mathrm{~L}$ del ADN amplificado, sembrándose 10 L en un gel de agarosa (Invitrogen) al 2\% en buffer TAE $1 \mathrm{X}$ (Invitrogen) y los marcadores de peso molecular $100 \mathrm{bp}$ Molecular Rule (BioRad, Hercules, CA, EE.UU.) y Cienmarker (Biodynamics S.R.L., Buenos Aires, Argentina). Se realizó la corrida electroforética a $8 \mathrm{~V} / \mathrm{cm}$ (Labnet) durante $50 \mathrm{~min}$. Posteriormente el gel fue sumergido en una suspensión de bromuro de etidio 0.5 $\mathrm{g} / \mathrm{ml}$ (Promega) durante $3 \mathrm{~min}$. Para documentar el gel se utilizó un transiluminador TFX-20M (Vilbert Lourmat, Marne-la-Vallée Cédex, Francia).

Se realizó el análisis descriptivo de las variables en estudio y el cálculo de las medidas de tendencia central mediante el uso del paquete estadístico informatizado Epi Info ${ }^{\mathrm{TM}}$ 3.5.4. (Centers for Disease Control and Prevention. 2010).

Para garantizar los aspectos éticos de la investigación los datos personales fueron encriptados respetando la confidencialidad de los sujetos participantes atendiéndose especialmente a lo normado por la Ley Nacional No 25326 de protección de datos personales. Los propietarios de los animales dieron su consentimiento por escrito y las prácticas se ajustaron a las normas estándar de cuidado y uso de animales: Ley Nacional 14346 sobre malos tratos y actos de crueldad a los animales (1954).

\section{Resultados}

El 59.3\% (96) de los animales muestreados correspondieron a especimenes caninos, con edades comprendidas entre los 6 meses y 11 años, una media de 31.8 meses, mediana de 24 meses y un desvío standard de 26.7 meses. 
Con respecto al sexo el $90.6 \%$ resultaron hembras, mientras que el $9.4 \%$ fueron machos.

Las razas de los perros (reportadas solo en 91 fichas) fueron: mestizo (mezcla de razas) $85.7 \%$, labrador $4.4 \%$, caniche $2.2 \%$, collie $2.2 \%$, boxer $1.1 \%$, dogo $1.1 \%$, fox terrier $1.1 \%$, ovejero alemán $1.1 \%$ y rottweiler $1.1 \%$.

La alimentación a base de alimento balanceado fue del $45.7 \%$ para la población canina estudiada mientras que los que consumían alimento no balanceado resultaron en el $8.7 \%$. El $45.7 \%$ restante ingerían alimentación mixta.

El lugar de residencia de los animales se muestra en la figura 1 .

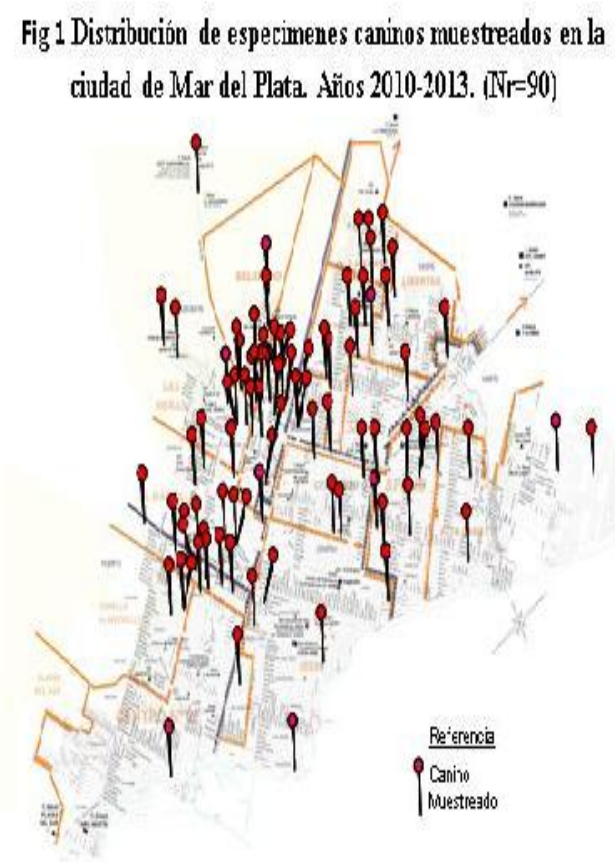

Sólo el $1.0 \%$ de los animales presentó diarrea en los 15 días previos a la toma de muestra, en tanto que ninguno de los propietarios como sus respectivas familias presentaron síntomas de diarrea en el mismo período.

En relación a la cohabitabilidad de los perros con seres humanos el $62.0 \%$ estaban en contactos con adultos y niños mientras que el $38.0 \%$ estaban en contacto con adultos.

En ninguna de las muestras procesadas se detectaron los genes que codifican para la producción de las toxinas Shiga 1 y $2\left(s t x_{1}\right.$, stx $\left.x_{2}\right)$ ni el gen $r f b_{0157}$ por la técnica de PCR múltiple

Los especímenes felinos estudiados (66) tenían edades comprendidas entre los 5 meses y 12 años, una media de 22.2 meses, una mediana de 8 meses y un desvío standard de 26.1 meses. El 51.5\% resultaron hembras, mientras que el $48.5 \%$ fueron machos.

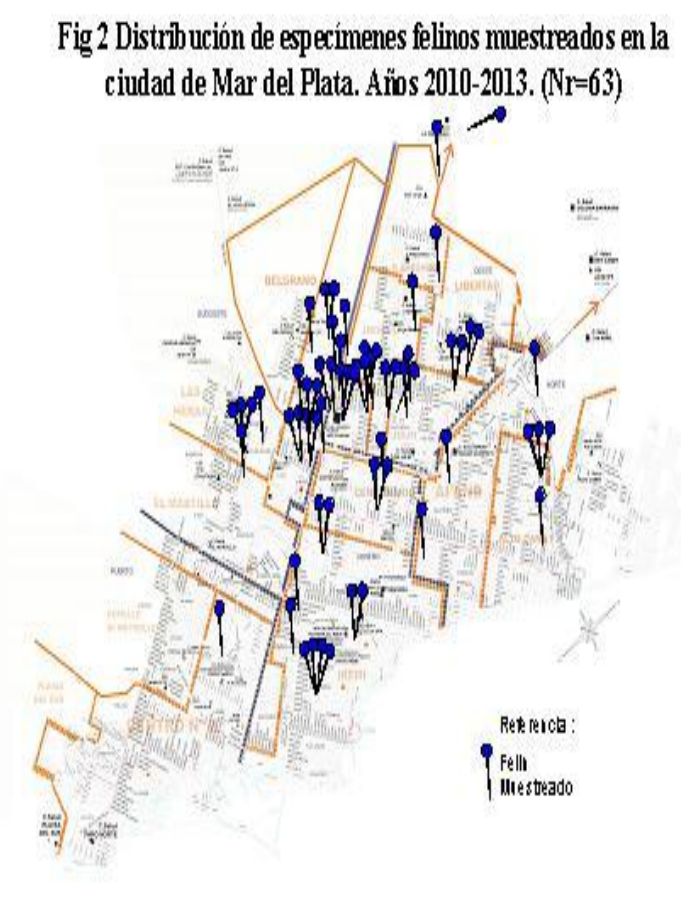

En la población felina estudiada, la alimentación a base de alimento balanceado fue del $59.7 \%$ para aquellos con alimento no balanceado resultó del $8.1 \%$ y alimentación mixta del $32.3 \%$.

La zona de residencia de los animales estudiados se muestra en la figura 2.

El 4.9\% de los animales presentó diarrea en los 15 días previos a la toma de muestra, en tanto que ni los propietarios ni sus respectivas familias presentaron síntomas de diarrea en el mismo período. 
El 60.0\% de los gatos estaban en contacto con adultos y niños y el $40.0 \%$ restante solo lo estaban con adultos.

No se detectó señal positiva por PCR para los genes $s t x_{1}, s t x_{2}$ ni para el gen $r f b_{0157}$ en las muestras procesadas.

\section{Discusión}

La distribución georreferenciada de los animales muestreados, tanto perros como gatos, estableció que los mismos residían en barrios localizados en sectores céntricos como así también en sectores más periféricos de la ciudad de Mar del Plata, cuyo índice socioeconómico de la población residente (Celemin 2012) tiende a disminuir desde el centro urbano hacia la periferia.

Si bien algunas mascotas presentaron sintomatología diarreica es motivo de consideración en el presente trabajo que ninguno de los propietarios como sus respectivas familias presentaron síntomas de diarrea en los 15 días previos a la toma de muestra en los animales estudiados.

Podría suponerse un grado de cuidado por parte de los dueños hacia sus mascotas a partir de la decisión de castración de las mismas, como así también que la alimentación brindada era principalmente con alimentos balanceados por lo cual podría suponerse también un estado de higiene en las condiciones de cohabitabilidad con los mismos.

Dada la alta incidencia de casos de SUH en Argentina, antecedentes bibliográficos (Gallego et al.2006, Bentancor et al. 2006) y resultados previos, se esperaba detectar la presencia de Escherichia coli productor de toxina Shiga (STEC) en las especies estudiadas. Por ello también fue imposible correlacionar la potencialidad como factores de riesgo para adquirir y/o transmitir la infección con las variables 7 sometidas a estudio como género, raza, edad, alimentación, sintomatología y distribución geográfica de los mismos.

Una posible hipótesis para la ausencia de STEC en este estudio consistiría en que la alimentación en los animales estudiados (caninos y felinos) resultó principalmente con alimentos balanceados; quizás pueda considerarse esta circunstancia como uno de los factores determinantes para que no se haya aislado el microorganismo buscado en las muestras ya que el consumo de alimentos contaminados, como por ejemplo carne molida, productos cárnicos crudos o insuficientemente cocidos, constituyen una de las principales fuentes de infección para este microorganismo (Rivas et al. 2006). Podría reforzar esta suposición un trabajo realizado en perros, en el cual no se detectó STEC, los autores refirieron que la falta de resultados positivos para este microorganismo podría deberse a que los cuidados que se tienen con perros de zonas urbanas tales como administración de alimentos balanceados cuya elaboración implique procesos de cocción, alimentación con comidas cocidas preparadas por sus propietarios, ingestión de agua de bebida potable de red, permitirían reducir el contacto y colonización de estos caninos con este microorganismo (Fernández et al. 2006).

En función de los resultados obtenidos en este trabajo y la hipótesis planteada se concluye que sería recomendable el estudio de STEC en este tipo de animales de compañía pero en aquellos cuya alimentación no fuera a base de alimentos balanceados, sino que fuera por ejemplo de alimentos de tipo animal (a base de distintos cortes de carne y/o vísceras vacunas o de otra especie, crudas o semicocidas, restos de comidas, etc) con el propósito de mejorar el conocimiento de la transmisión de este microorganismo a partir de los animales de compañía como 
potenciales portadores, lo cual permitiría implementar nuevas estrategias de prevención y control de esta enfermedad.

\section{Conflictos de intereses}

Los autores declaran que no existen conflictos de interés.

\section{Agradecimientos}

Se agradece profundamente la colaboración de la Dra. Diana Gómez en el desarrollo del trabajo y al personal del Departamento de Zoonosis de la Municipalidad del Partido de General Pueyrredón por la toma de muestras.

\section{Literatura citada}

Bentancor A. El rol epidemiologico de las mascotas en el ciclo de transmisión urbana de cepas STEC. Medicina (Buenos Aires) 2006; 66 (Supl III): $37-41$.

Beutin L, Geier D, Steinruck H, Zimmermann S, Scheutz F. Prevalence and some properties of verotoxin (Shiga-like toxin) -producing Escherichia coli in seven different species of healthy domestic animals. J Clin Microbiol. 1993; 31:2483-2488.

Celemin JP. Asociación espacial entre fragmentación socioeconómica y ambiental en la ciudad de Mar del Plata, Argentina. EURE (Santiago). 2012; (38), 113: 33-51.

Centers for Disease Control and Prevention. Program Epi Info $^{\mathrm{TM}}$ version 3.5.4. Atlanta, United States of America. 2010. [Fecha de acceso 24 de marzo de 2014]. Disponible en: https://wwwn.cdc.gov/epiinfo/html/prevVersion.htm.
Doyle MP, Zhao T, Meng J, Zhao S. Escherichia coli O157:H7. In: Doyle MP, Beuchat LR, Montville TJ (Eds). Food Microbiology: fundamentals and frontiers. American Society for Microbiology. Washington DC. 1997; Cap 10: 171191.

Fernández D, Etcheverria AI, Padola NL, Parma AE. Estudio en caninos de zonas urbanas de Tandil como posibles portadores de Escherichia coli verocitotoxigénicos. In Vet 2006; 8:111117.

Franke S, Harmsen D, Caprioli A, Pierard D, Wieler Lh, Karch H. Clonal relatedness of Shiga-like toxin-producing Escherichia coli O101 strains of human and porcine origin. J Clin Microbiol. 1995; 33:3174-78.

Gallego V, Deza N, Carbonari C, Gugliada J, Stambulian J, Repetto H, et al. Detección de Escherichia coli productor de toxina Shiga (STEC) en adultos asintomáticos que conviven con mascotas. VI Congreso Argentino de la Sociedad Argentina de Infectologia. Mar del Plata, Argentina. 2006.

Grifin PM, Tauxe RV. The epidemiology of infections caused by Escherichia coli $\mathrm{O} 157: \mathrm{H} 7$, other enterohemorrhagic E. coli, and the associated hemolytic uremic syndrome. Epidemiol Rev. 1991; 13: 60-98.

Instituto Nacional de Estadísticas y Censos (INDEC), República Argentina. Censo Nacional de Población, Hogares y Viviendas (Censo 2010). [Fecha de acceso 24 de marzo de 2014]. Disponible en: http://www.censo2010.indec.gov.ar/resultadosdefinitivos.asp.

Kobayashi M, Sasaki T, Saito N, Tamura K, Susuki $\mathrm{K}$, Watanabe $\mathrm{H}$, et al. House flies: not simple mechanical vectors of enterohemorrhagic Esche- 
richia coli O157:H7. Am J Trop Med Hyg. 1999; 61:625-629.

Leotta GA, Chinen I, Epszteyn S, Miliwebsky E, Melamed I, Motter M, et al. Validación de una técnica de PCR múltiple para la detección de Escherichia coli productor de toxina Shiga. Rev Argent Microbiol. 2005; 37: 1-10.

Leotta GA, Deza N, Origlia J, Toma C, Chinen I, Miliwebsky E et al. Detection and characterization of Shiga toxin-producing Escherichia coli in captive non-domestic mammals. Vet Microbiol. 2006; 118:151-157.

Nataro JP, Kaper JB. Diarrheagenic Escherichia coli. Clinical Microbiology Reviews. 1998; 11: 142-201.
Rivas M, Chinen I, Miliwebsky E, Galli L, Repetto HA, Masana MO. Epidemiology of Argentinean STEC. In: Bacterial Population Genetics: A Tribute to Thomas S. Whittam. eds Walk ST, Feng PCH. Washington, DC: ASM Press. 2011; 109-132.

Rivas M, Miliwebsky E, Chinen I, Deza N, Leotta G. Epidemiología del síndrome urémico hemolítico en Argentina. Diagnóstico del agente etiológico, reservorios y vías de transmisión. Medicina (Buenos Aires). 2006; 66 (Supl. III): 27-32.

Trevena WB, Hooper RS, Wray C, Willshaw GA, Smith HR, Cheasty T, et al. Vero cytotoxinproducing Escherichia coli $\mathrm{O} 157$ associated with companion animals. Vet Rec. 1996; 138:40. 